\title{
Evaluation of Changes in the Smoking Habits of Patients with Coronavirus Disease-19
}

\author{
Derya Yenibertiz ${ }^{1 *}$, Berna Akıncı Özyürek ${ }^{2}$, Tijen Şengezer ${ }^{3}$, Enes Gökler ${ }^{4}$, Gizem Söğütlük Dığrak ${ }^{3}$, \\ Filiz Koç ${ }^{5}$
}

${ }^{1}$ Department of Pulmonology, University of Health Sciences, Keçiören Training and Research Hospital, Ankara, Turkey ${ }^{2}$ Department of Pulmonology, University of Health Sciences, Ataturk Chest Diseases and Chest Surgery Training and Research Hospital, Ankara, Turkey

${ }^{3}$ Department of Family Medicine, University of Health Sciences, Keçioren Training and Research Hospital, Pulmonology, Ankara, Turkey

${ }^{4}$ Department of Public Health, University of Ylldirm Beyazt, Ankara, Turkey

${ }^{5}$ Department of Infectious Diseases and Clinical Microbiology, University of Health Sciences, Keciören Training and Research Hospital, Ankara, Turkey

\begin{abstract}
The purpose of our study was to determine the changes in the smoking habits of active smokers hospitalized with Coronavirus disease-19 (Covid-19).

We conducted a single-center, retrospective research on smokers hospitalized with Covid-19 between March 2020 and June 2020. A total of 105 patients were included in the study. The age, gender, comorbidities, cigarette pack per year, PCR test results of the patients were recorded from the patient files. Patients were approached by telephone and a questionnaire was applied to them to evaluate smoking habits following discharge.

A total of 105 patients participated in the study. $42(40.0 \%)$ were female and the mean age of the patients was $39.80 \pm$ 12.66 (width, 16-69) years. Patients smoked $14.51 \pm 13.88$ packs of cigarettes a year on average. Of the patients, $13.33 \%$ quit smoking. In our study, it was determined that after having Covid-19, 86.66\% (n: 91) of the patients continued to smoke. Of those who did not quit smoking, $53.8 \%$ stated that they reduced smoking compared to the past, $76.9 \%$ thought to quit smoking, and $48.4 \%$ said they needed professional support to quit smoking. In addition, $38.5 \%$ of those who didn't quit smoking stated that they believed they were caught Covid-19 due to smoking.

Raising awareness that quitting smoking reduces the risks and complications of Covid-19 and activating new smoking cessation programs may help individuals to quit smoking during the pandemic.
\end{abstract}

Key Words: Covid-19, smoking, smoker

\section{Introduction}

Smoking (consumption of tobacco) has been maintained its importance due to its causal relationship with many respiratory diseases for years and its negative impacts on the prognosis of diseases, health, social, economic, and environmental conditions have been known for a long time (1).

The association of smoking with Covid-19 has also come into doubt during the pandemic, which has been on the world's agenda since December 2019. Covid-19 can lead to severe acute respiratory failure syndrome and the main cause of death for these patients is respiratory failure. Tobacco smoke exposure worsens the immune system's response to infections and makes smokers more vulnerable to infectious diseases (2).

Smokers are reported to be twice as likely to get influenza and have more severe symptoms than non-smokers (3). Smokers are at higher risk of having Covid-19 and these patients are also at higher risk of developing serious complications of Covid-19 (4). It has been reported that smoking cessation reduces the risk of Covid-19 as well as the possibility of developing severe Covid-19 complications (5).

${ }^{*}$ Corresponding Author: Derya Yenibertiz, University of Health Sciences, Keçiören Training and Research Hospital, Ankara, Turkey E-mail: yenibertizderya@gmail.com, Phone: +90 3123569000, Fax: +90 3123569022 
Table 1. The distribution of some sociodemographic characteristics of the patients according to the smoking cessation status following Covid-19

\begin{tabular}{|c|c|c|c|c|c|}
\hline & & & Not quit smoking & Quit smoking & $\mathrm{X} 2 / \mathrm{Z} ; \mathrm{p}$ \\
\hline \multirow{2}{*}{ Gender } & Female & $\mathrm{n}(\%)$ & $38(41.76)$ & $4(28.57)$ & \multirow{2}{*}{$0.879 ; 0.348$} \\
\hline & Male & $\mathrm{n}(\%)$ & $53(58.24)$ & $10(71.43)$ & \\
\hline Age & & $\begin{array}{c}\text { median } \\
(\text { IQR 25-75) }\end{array}$ & $\begin{array}{c}39.00 \\
(29,00-48,00)\end{array}$ & $\begin{array}{c}42.50 \\
(32.00-49.00)\end{array}$ & $1.259 ; 0.208$ \\
\hline Cigarette pack/year & & $\begin{array}{c}\text { median } \\
(\text { IQR 25-75) }\end{array}$ & $\begin{array}{c}10.00 \\
(5.00-20.00)\end{array}$ & $\begin{array}{c}7.50 \\
(2.00-20.00)\end{array}$ & $0.530 ; 0.536$ \\
\hline Comorbidities & $\begin{array}{l}\text { No } \\
\text { Yes }\end{array}$ & $\begin{array}{l}\text { n (\%) } \\
\text { n (\%) }\end{array}$ & $\begin{array}{l}56(61.54) \\
35(38.46)\end{array}$ & $\begin{array}{c}11(78.57) \\
3(21.43)\end{array}$ & $1.524 ; 0.217$ \\
\hline
\end{tabular}

Unfortunately fear of respiratory failure and death arise in patients infected with new coronavirus (SARS-COV-2) which affects the whole world. Especially the increased anxiety level in smoker patients may cause changes in smoking habits.

In this study, it was aimed to evaluate the changes in smoking habits of active smokers hospitalized with Covid-19 in our hospital between March 2020 and June 2020 during the Covid-19 pandemic.

\section{Material and Methods}

We conducted a single-center, retrospective research on active smokers hospitalized in our hospital with Covid-19 between March 2020 and June 2020. The study included a total of 105 patients with Covid-19 who agreed to participate, who responded to the questionnaire, who gave verbal consent, who were able to communicate and who were over 18 years of age. Patients who refused to participate in the study and to respond to the questionnaire, whose data were incomplete, who could not be contacted, who had another diagnosis during hospitalization, who did not smoke or quit smoking, who did not want to give detailed anamnesis about their smoking habits and who could not be contacted by telephone were excluded from the study. The age, gender, comorbidities, cigarette pack per year, PCR test results of patients with Covid-19 included in the study were recorded from the patient files. Ethics committee approval was received from the Ethics committee of our hospital (Approval date and number: 24.06.2020/ 2012-KAEK-15/2120. Smoker patients with Covid-19 were contacted by telephone and a questionnaire was applied to evaluate the patients' smoking habit following discharge. Detailed informations were given to the patients about the research which we intended to do, verbal consent was obtained, and voluntary patient responses were registered. The questions in the questionnaire form applied to the patients are as follows:

- Is your smoking decreased compared to the past?

- Are you considering to quit smoking?

- Do you need professional support to quit smoking?

- Do you believe you had Covid 19 because of smoking?

\section{Statistical Analysis}

The data obtained were evaluated using IBM-SPSS (Version 22.0) statistics package program in a computer environment. Number, percentage, mean \pm standard deviation (SD), median, minimum (min), maximum (max), and median interquartile range (IQR 25-75) were used for descriptive statistics. Chi-square test was used in the comparison of categorical data, Shapiro-Wilk test was used in the comparison of continuous data. Mann-Whitney $U$ test was used as a consequence of the normality test by evaluating its suitability for normal distribution. For statistical significance, $\mathrm{p}<0.05$ was accepted.

\section{Results}

A total of 105 patients involved in the study. Of these, $42(40.0 \%)$ were female, 63 of them $(60.0 \%)$ were male, and the mean age of the patients was $39.80 \pm 12.66$ (width, 16-69) years. Patients smoked an average of $14.51 \pm 13.88$ packs of cigarettes per year. $13.33 \%$ of the patients had quit smoking. No relationship was found between the status of smoking cessation and gender, age, duration of smoking, and comorbidities ( $p>0.05$ for each). The distribution of some sociodemographic characteristics according to the smoking cessation status of the patients following Covid-19 is presented in table 1. 
Table 2. The distribution of comorbidities of patients according to smoking cessation after having Covid-19

\begin{tabular}{lccccc}
\hline Comorbidities & & & Not quit smoking & Quit smoking & X2; p \\
\hline DM & No & $\mathrm{n}(\%)$ & $86(94.5)$ & $12(85.7)$ & $1.507 ; 0.220$ \\
& Yes & $\mathrm{n}(\%)$ & $5(5.5)$ & $2(14.3)$ & \\
HT & No & $\mathrm{n}(\%)$ & $78(85.7)$ & $14(100.0)$ & $2.283 ; 0.131$ \\
& Yes & $\mathrm{n}(\%)$ & $13(14.3)$ & $0(0.0)$ & \\
CAD & No & $\mathrm{n}(\%)$ & $83(91.2)$ & $13(92.9)$ & $0.042 ; 0.837$ \\
& Yes & $\mathrm{n}(\%)$ & $8(8.8)$ & $1(7.1)$ & \\
COPD & No & $\mathrm{n}(\%)$ & $89(97.8)$ & $14(100.0)$ & $0.314 ; 0.575$ \\
& Yes & $\mathrm{n}(\%)$ & $2(2.2)$ & $0(0.0)$ & \multirow{2}{*}{ Cancer } \\
\multirow{2}{*}{ Others } & No & $\mathrm{n}(\%)$ & $82(90.1)$ & $14(100.0)$ & $1.514 ; 0.218$ \\
& Yes & $\mathrm{n}(\%)$ & $9(9.9)$ & $0(0.0)$ & \multirow{2}{*}{$0.808 ; 0.369$} \\
& No & $\mathrm{n}(\%)$ & $86(94.5)$ & $14(100.0)$ & \\
\hline
\end{tabular}

The additional disease was found in $36.2 \%$ of the research population. When the smoking cessation status of patients after having Covid-19 and their additional diseases were compared, no relationship was found among smoking cessation status of those with diabetes mellitus (DM), hypertension $(\mathrm{HT})$, coronary artery disease (CAD), chronic obstructive pulmonary disease (COPD) and cancer patients or without them ( $p>0.05$ for each). The distribution of smoking cessation status after having Covid-19 and comorbidity of patients is presented in Table 2.

The most common symptoms were fever (49.5\%), myalgia $(33.3 \%)$, and cough $(29.5 \%)$ in the research population. Only 9 of the patients did not have any symptoms. When the correlations between the patients' smoking cessation status after having Covid-19 and the presence of symptoms were examined, it was found that those with dyspnea and with less cough quit smoking (p: $<0.001$, p: 0.049 , respectively). The distribution of smoking cessation status and the presence of symptoms after having Covid-19 is presented in Table 3.

In our study, it was determined that $86.66 \%$ (n: 91) of the individuals continued to smoke after having Covid -19. Of those who did not quit smoking, 53.8\% stated that they reduced smoking compared to the past, $76.9 \%$ thought to quit smoking, and $48.4 \%$ said they needed professional support to quit smoking. In addition, $38.5 \%$ of those who didn't quit smoking stated that they believed they were caught Covid-19 due to smoking. The distribution of the opinions of those who did not quit smoking in the research population about smoking is presented in Table 4 .

\section{Discussion}

Covid-19 especially affects the respiratory tract like smoking by settling down in the upper respiratory tract through the mouth and nose (6). More serious complications may develop in smoker patients with Covid-19. The relationship between smoking and Covid-19 was explored in the review of five studies by comparing smoker patients with covid-19 and non-smoker patients with Covid-19 and there were 1.4 times more severe symptoms, 2.4 times more intensive care unit requirements, mechanical ventilation, and death in the smoker Covid-19 patients (4). In our study, we found that patients with dyspnea quit smoking more. We assume this is due to the fact that dyspnea is a severe symptom among the Covid-19 symptoms and increases anxiety by impairing quality of life.

We determined that $13.33 \%$ of the patients quit smoking in our research. In the study of D'Angelo et al., the 1-year smoking cessation rate was found to be $23.7 \%$ (7), while it was found as $19 \%$ with medical treatment and intensive motivational support in the study of West et al. (8). In another study carried out by Tetik et al. investigating the effect of coronavirus on smoking cessation habit, the rate of smoking cessation during the pandemic period was found to be $31.1 \%$ (9). In our research, the smoking cessation rate spans a period of 3.5 months and we believe that this rate will increase as data is received over the year.

Most smokers claim that smoking relaxes them and they smoke more during stressful periods of their lives (9). Therefore, some of the patients may not alter their smoking habit during the pandemic period. In our study, there was no decrease in the smoking rate in about half of the patients. This

East J Med Volume:26, Number:1, January-March/2021 
Table 3. The distribution of smoking cessation status and presence of symptoms after having Covid-19 disease

\begin{tabular}{|c|c|c|c|c|c|}
\hline & & & Not quit smoking & Quit smoking & $\mathrm{X} 2 ; \mathrm{p}$ \\
\hline \multirow[t]{2}{*}{ Fever } & No & n $(\%)$ & $44(48.4)$ & $9(64.3)$ & \multirow{2}{*}{$1.232 ; 0.267$} \\
\hline & Yes & n $(\%)$ & $47(51.6)$ & $5(35.7)$ & \\
\hline \multirow[t]{2}{*}{ Dyspnea } & No & $\mathrm{n}(\%)$ & $73(80.2)$ & $5(35.7)$ & \multirow{2}{*}{$12.581 ;<0.001$} \\
\hline & Yes & $\mathrm{n}(\%)$ & $18(19.8)$ & $9(64.3)$ & \\
\hline \multirow[t]{2}{*}{ Malaise } & No & n $(\%)$ & $70(76.9)$ & $11(78.6)$ & \multirow{2}{*}{$0.019 ; 0.891$} \\
\hline & Yes & n $(\%)$ & $21(23.1)$ & $3(21.4)$ & \\
\hline \multirow[t]{2}{*}{ Headache } & No & n $(\%)$ & $85(93.4)$ & $14(100.0)$ & \multirow{2}{*}{$0.979 ; 0.322$} \\
\hline & Yes & $\mathrm{n}(\%)$ & $6(6.6)$ & $0(0.0)$ & \\
\hline \multirow[t]{2}{*}{ Throat ache } & No & n $(\%)$ & $73(80.2)$ & $10(71.4)$ & \multirow{2}{*}{$0.566 ; 0.452$} \\
\hline & Yes & n $(\%)$ & $18(19.8)$ & $4(28.6)$ & \\
\hline \multirow[t]{2}{*}{ Cough } & No & n $(\%)$ & $61(67.0)$ & $13(92.9)$ & \multirow{2}{*}{$3.889 ; 0.049$} \\
\hline & Yes & n $(\%)$ & $30(33.0)$ & $1(7.1)$ & \\
\hline \multirow[t]{2}{*}{ Myalgia } & No & n $(\%)$ & $60(65.9)$ & $10(71.4)$ & \multirow{2}{*}{$0.165 ; 0.685$} \\
\hline & Yes & n $(\%)$ & $31(34.1)$ & $4(28.6)$ & \\
\hline \multirow[t]{2}{*}{ Diarrhea } & No & $\mathrm{n}(\%)$ & $83(91.2)$ & $14(100.0)$ & \multirow{2}{*}{$1.332 ; 0.248$} \\
\hline & Yes & n $(\%)$ & $8(8.8)$ & $0(0.0)$ & \\
\hline \multirow[t]{2}{*}{ Nausea-Vomiting } & No & n $(\%)$ & $88(96.7)$ & $14(100.0)$ & \multirow{2}{*}{$0.475 ; 0.491$} \\
\hline & Yes & n $(\%)$ & $3(3.3)$ & $0(0.0)$ & \\
\hline \multirow[t]{2}{*}{ Loss of taste and smell } & No & n $(\%)$ & $86(94.5)$ & $14(100.0)$ & \multirow{2}{*}{$0.808 ; 0.369$} \\
\hline & Yes & $\mathrm{n}(\%)$ & $5(5.5)$ & $0(0.0)$ & \\
\hline \multirow[t]{2}{*}{ At least 1 symptom } & No & n $(\%)$ & $9(9.9)$ & $0(0.0)$ & \multirow{2}{*}{$1.514 ; 0.218$} \\
\hline & Yes & $\mathrm{n}(\%)$ & $82(90.1)$ & $14(100.0)$ & \\
\hline
\end{tabular}

Table 4. The distribution of smoking-related thoughts of those who did not quit smoking in the research population

\begin{tabular}{lllc}
\hline & & & Not quit smoking \\
\hline Is your smoking decreased compared to the past? & Yes & $\mathrm{n}(\%)$ & $49(53.8)$ \\
Are you considering quitting smoking? & No & $\mathrm{n}(\%)$ & $42(46.2)$ \\
& Yes & $\mathrm{n}(\%)$ & $70(76.9)$ \\
Do you need professional support to quit smoking? & No & $\mathrm{n}(\%)$ & $21(23.1)$ \\
& Yes & $\mathrm{n}(\%)$ & $44(48.4)$ \\
Do you believe you had Covid-19 because of smoking & No & $\mathrm{n}(\%)$ & $47(51.6)$ \\
& Yes & $\mathrm{n}(\%)$ & $35(38.5)$ \\
& No & $\mathrm{n}(\%)$ & $56(61.5)$ \\
\hline
\end{tabular}

may be because the vast majority of patients $(61.5 \%)$ think that smoking isn't one of the factors that cause coronavirus disease.

The risk factors associated with the severe course and mortality of Covid -19 are male gender, advanced age, smoking, obesity, and the presence of comorbid diseases (HT, DM, COPD, CAD, chronic liver disease, CVO, dementia) (10). The most common comorbid disease is hypertension . More deaths due to Covid-19 have been observed in patients with COPD and smoker patients (11). In $36.2 \%$ of our patients, at least one additional disease was present and the most common accompanying disease was HT in accordance with the literature. We did not find a relationship between comorbidities and smoking cessation habit following Covid-19. This is because of the average age of our patient group was younger $(39.80 \pm 12.66)$ and the general condition of the patients were fine because they had a single additional disease. We think that this was due to 
the curfews applied to individuals over the age of 65 during the pandemic management in our country at that time.

Smoking can cause chronic illnesses and decrease the quality of life. It is one of the most important preventable causes of mortality (12). It was found that mostly men apply to smoke cessation polyclinics according to several reports (13-16). We detected that most of the patients who quit smoking following covid-19, were men. This was probably due to the higher number of men in the research population and the fact that the disease was known to have a more severe course in men. Also, as women experience more stress during this period, it may be more difficult for them to quit smoking (17).

In a study, it was shown that GOOGLE searches associated with smoking cessation increased in late February and March (18). In our study $76.9 \%$ of smoker patients stated that they were considering to quit smoking following Covid-19. The success of smoking cessation will increase if physicians provide sufficient motivational support and recommend pharmacotherapy to patients during this period. The method of telemedicine and social media platform will also be very useful too.

Effective results may occur when significant attempts are carried out to quit smoking in smoker patients with Covid-19. In this context, it is important to provide clear and strong recommendations and to support the patient by healthcare professionals.

Raising awareness that quitting smoking reduces the risks and complications of Covid-19 and activating new smoking cessation programs may help individuals to quit smoking during the pandemic.

Conflict of Interest: Authors declared no conflict of interest or financial support

\section{References}

1. Tonnesen P, Marott JL, Nordestgaard B, Bojesen SE, Lange P. Secular trends in smoking in relation to prevalent and incident smoking-related disease: A prospective population-based study. Tob Induc Dis 2019; 17: 72 .

2. Berlin I, Thomas D, Le Faou AL, Cornuz J. COVID-19 and Smoking. Nicotine Tob Res 2020; 22: 1650-1652.

3. Arcavi L, Benowitz NL. Cigarette smoking and infection. Arch Intern Med 2004; 164: 2206-2216.
4. Vardavas CI, Nikitara K. COVID-19 and smoking: A systematic review of the evidence. Tob Induc Dis 2020; 18: 20.

5. Eisenberg SL, Eisenberg MJ. Smoking Cessation During the COVID-19 Epidemic. Nicotine Tob Res 2020; 22: $1664-$ 1665.

6. Strzelak A, Ratajczak A, Adamiec A, Feleszko W. Tobacco Smoke Induces and Alters Immune Responses in the Lung Triggering Inflammation, Allergy, Asthma and Other Lung Diseases: A Mechanistic Review. Int J Environ Res Public Health 2018: 15: 1033. Published 2018 May 21.

7. D'Angelo, MES, Reid, R, et al. Gender Differences in Predictors for Long-term Smoking Cessation Following Physician Advice and Nicotine Replacement Therapy. Can J Public Health 2001; 92: 418422.

8. West R., McNeill A., Raw M. Smoking cessation guidelines for health professionals: an update. Health Education Authority. Thorax 2000; 55: 987-999.

9. Kayhan TB, Gedik TI, Taş S. The Effect of the COVID-19 Pandemic on Smoking Cessation Success [published online ahead of print, 2020 Jul 8]. J Community Health 2020; $1-5$.

10. Wu Z, McGoogan JM. Characteristics of and Important Lessons from the Coronavirus Disease 2019 (COVID-19) Outbreak in China: Summary of a Report of 72314 Cases from the Chinese Center for Disease Control and Prevention. JAMA - J Am Med Assoc 2020; 323: 1239-1242.

11. Kumar R., Prasad R. Smoking cessation: an update. Indian J Chest Dis Allied Sci 2014; 56: 161-169.

12. Simon JA, Carmody TP, Hudes ES, Snyder E, Murray J. Intensive smoking cessation counseling versus minimal counseling among hospitalized smokers treated with transdermal nicotine replacement: a randomized trial. Am J Med 2003; 114: 555-562.

13. Arguder E., Karalezli A., Hezer H. et al. Factors Affecting the Success of Smoking Cessation Turkish journal of tuberculosis \& thorax 2013; 14: 81-87

14. Can G, Oztuna F, Topbaş M. Complaints related to smoking cessation. Turkish journal of tuberculosis \& thorax 2007; 55: 364-369.

15. Saglam L. Investigation of the results of a smoking cessation clinic and the factors associated with success. Turkish Journal of Medical Sciences 2012; 42: 515-522.

16. Mutlu P, Yildırım BB, Acıkmese B. Results taken from a smoking cessation clinic at a

East J Med Volume:26, Number:1, January-March/2021 
second-level state hospital. Istanbul Medicine Journal 2015; 16: 145-148.

17. Elling JM, Crutzen R, Talhout R, De Vries H. Tobacco smoking and smoking cessation in times of COVID-19. Tobacco Prevention \& Cessation 6 no. July 2020: 6(July): 39
18. Heerfordt C., Heerfordt IM. Has there been an increased interest in smoking cessation during the first months of the COVID-19 pandemic? A Google Trends study. Public Health 2020; 183: 6-7. 